\title{
Adhesiolysis and Decortication for Reccurent Hydropneumothorax Associated with Pleural Tuberculosis
}

\author{
Muhamad Yusuf Musthafa', Yani Jane Sugiri', Imam Suseno Bayuadi2 \\ ${ }^{1}$ Department of Pulmonology and Respiratory Medicine Faculty of Medicine Brawijaya University, dr. Saiful Anwar Hospital \\ Malang \\ ${ }^{2}$ Department of Thoracic and Cardiovascular Surgery Medicine Faculty of Medicine Brawijaya University, dr. Saiful Anwar
}

Hospital Malang

\begin{abstract}
Introduction: Pleural tuberculosis is a pleural infection of tuberculosis caused by Mycobacterium tuberculosis which commonly manifests as hydropneumothorax. Initial treatment with anti-tuberculosis drugs is aimed to prevent progression of the disease and relieve patient's symptoms. Indication of adhesiolysis and decortication is to remove layer of fibrous tissue and allow the lung to reexpand.

Case: A 60 year old woman with shortness of breath, cough, and right-sided chest pain. She had a history of treatment with first-line anti-tubercular drugs for a year stop in September 2016. She was identified with recurrent right-sided hydropneumothorax by chest imaging and thorax CT-scan. Adhesiolysis and decortication were performed on her. Two months later she was diagnosed again with recurrent right-sided hydropneumothorax. VATS (Video-Assisted Thoracoscopic Surgery) revealed fistula involving inferior lobe of the lung. Then, she was treated with second-line anti tuberculosis drugs. After four times reccurent hydropneumothorax, patient showed significant improvement in clinical condition, radiology finding, and lung function test after she finished the tuberculosis treatment.

Discussion: Definitive diagnosis of pleural tuberculosis is by the finding of mycobacterium tuberculosis in pleural biopsy, or Mtb culture, and it was difficult to perform. In this case pleural fluid analysis revealed that cause of recurrent right-sided hydropneumothorax was tuberculosis infection.

Summary: A 60 year old woman with four times reccurent right-sided hydropneumothorax, and the pleural fluid analysis suggested it was tuberculosis infection. Providing anti-tuberculosis medication based on clinically diagnosed tuberculosis based on flowchart of tuberculosis diagnosis from national tuberculosis programmed are essential to prevent progression of the disease.
\end{abstract}

Key words: Hydropneumothorax, Pleural tuberculosis, Adhesiolysis, Decortication.

\section{Introduction}

Pleural tuberculosis is a pleural infection of tuberculosis caused by mycobacterium tuberculosis which commonly manifests as hydropneumothorax ${ }^{1}$ Radiologic examination is needed to establish intrapulmonary lession ${ }^{2}$. Adhesiolysis and
MRJ 2021; 03(02):157-161 decortication are the surgical therapeutic modalities for reccurent hydropneumothorax. Decortication is a surgical procedure that removes a restrictive layer of fibrous tissue overlying the lung, chest wall and diaphragm. Indication of adhesiolysis and decortication is to remove layer, divide adhesions and to allowed the lung to be reexpanded. ${ }^{3}$ Initial

${ }^{*}$ Corresponding author:

Muhamad Yusuf Mustafa (yusuf.musthafa.ym@gmail.com)

Departement of Pulmonology and Respiratory Medicine Medical Faculty of Brawijaya, Dr. Saiful Anwar Hospital, Malang 
treatment with antituberculosis drugs is aimed to prevent progession of the disease and relieve patient's symptoms. ${ }^{4}$

\section{Case History}

A woman 60 years old has complained shortness of breath. She has a history of tuberculosis at 2016 and got OAT $1^{\text {st }}$ category for a year. The physical examination showed decrease of stem fremitus, and decrease of breath soung in right hemithorax. Physical examination also showed dullness in percussion at right side. The doctor perform some laboratorium and radiological examination. The result of laboratory finding within normal limit, while chest x-ray and thorax CT-scan showed hydropneumothorax dextra (figure 1). The sputum rapid molecular examination at october $10^{\text {th }} 2017$ showed M.tuberculosis not detected. The patient also perform bronchoscopy, and the result was stenoting compresive of the medial and lower lobe right bronchus suggested extra lumen compression. Rapid molecular test with bronchoalveolar lavage sample at October $11^{\text {th }} 2017$ also showed M.tuberculosis not detected. At october 2017, chest tube insertion was performed due to lung collapse, and after lung reexpand, the doctor continued with pleurodesis with bleomicyn. Unfortunately, at january 2018 the patient had right-sided hydropneumothorax reccurent, and the doctor plans for thoracotomy exploration to find out the cause of it. The result of thoracotomy exploration, there wa adhesion between superior and inferior lobe, adhesion between inferior lobe and diaphragm. Then adhesiolysis and decortication were performed and allow the lung to reexpand (figure 2). At April 2018, the patient had complained of shortness of breath again, and the doctor was perform chest x-ray and thorax CT-scan that showed reccurent hydropneumohorax dextra (figure $3)$. Then the doctor performed of chest tube insertion and VATS (Video Assisted Thoracoscopy Surgery). The result of VATS, multiple fistulas are obtained in the right inferior lobe of the lung and lung adhesions with thoracic wall. Repair fistulas and pleurodesis were performed. After that, the physician decided to providing the patient with OAT 2nd category. 

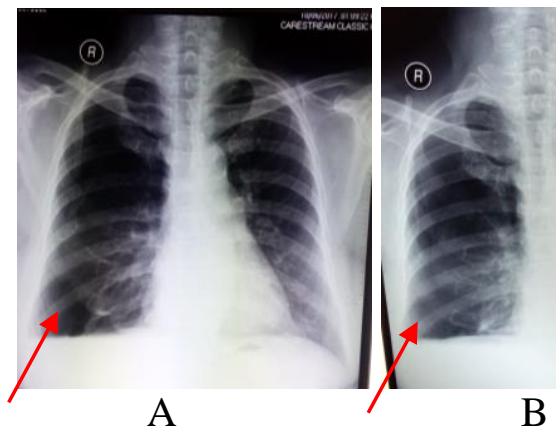

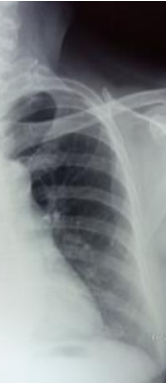

B

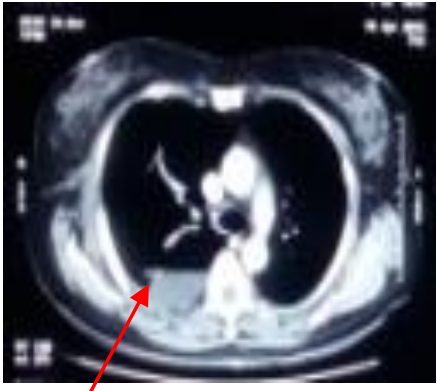

$\mathrm{C}$

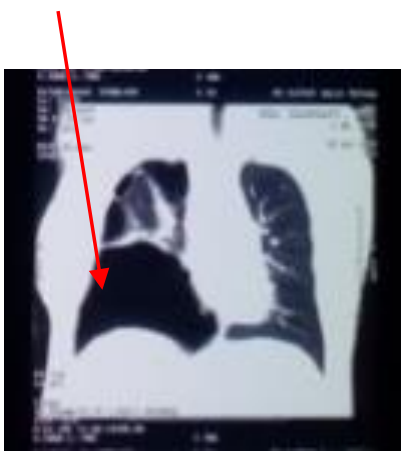

$\mathrm{D}$

Figure 1. Radiology Imaging

A. Chest x-ray on october $6^{\text {th }} 2017$ shows hydropneumothorax dextra, B. cxr was taken on Pebruary $8^{\text {th }} 2018$ and diagnosed with reccurent hydropneumothorax dextra. C. Thorax ct-scan at october 2017 revealed right-sided hydropneumothorax.

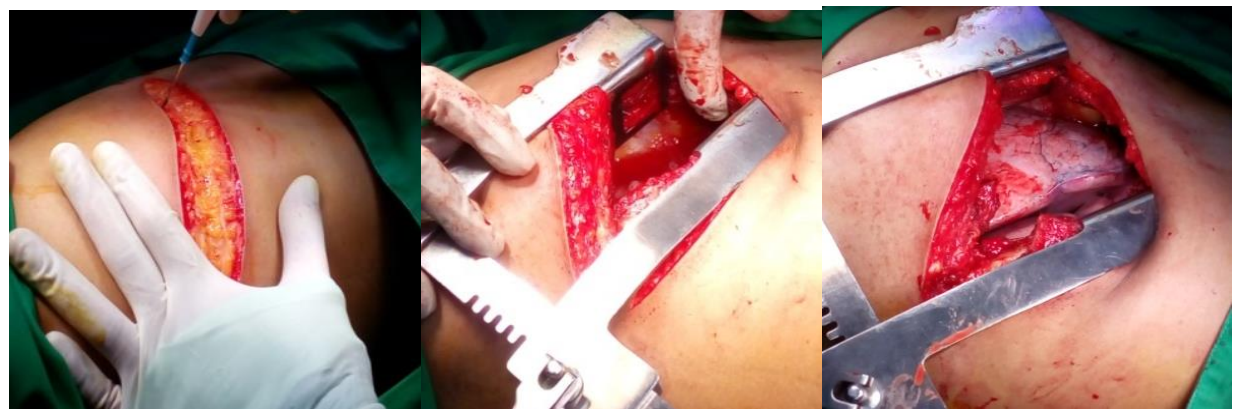

A B

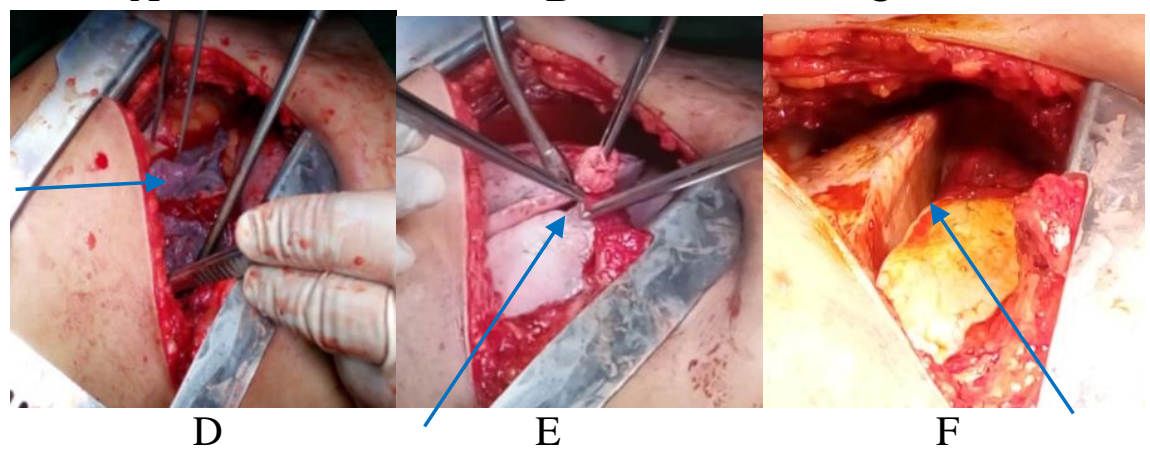

Figure 2. Thoracotomy exploration

A. open thoracotomy, deep layer by layer, B. Open the thoracic cavity with a chest retractor, C. Obained the superior and inferior lobes of right lung didn't expand, D. Adhesion between the superior and inferior lobes, adhesion of inferior lobes and the diaphragm, E. Decortication and adhesioolysis between the superior and inferior lobes, the inferior lobe the diaphragm, F. Pleurodesis right thoracic cavity.

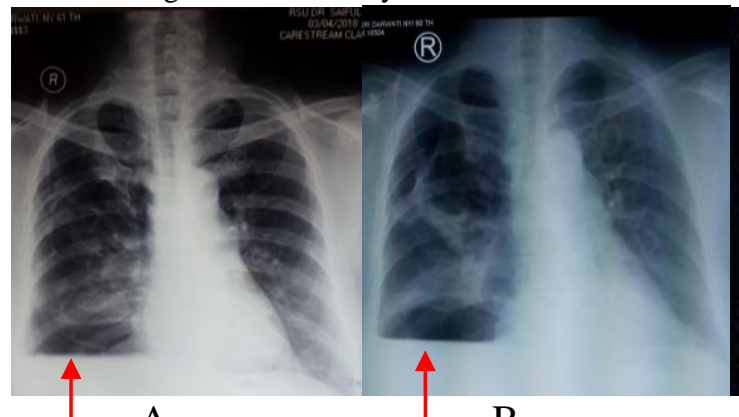

A

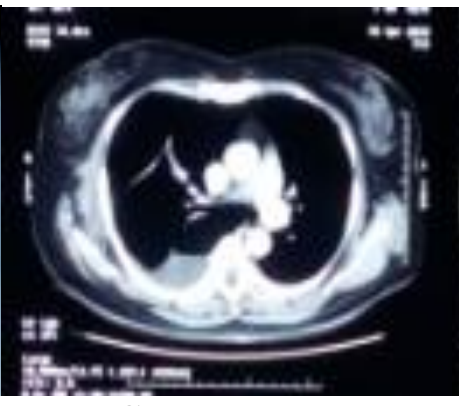

C

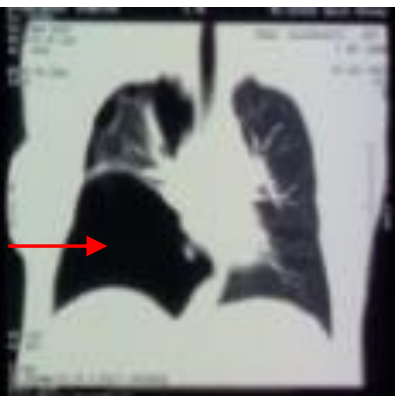

$\mathrm{D}$

Figure 3. Radiology Imaging (After Thoracotomy)

$\mathrm{A}$ and B are chest X-ray on april $3^{\text {th }}$ and may $18^{\text {th }} 2018$, that shows reccurent hydropneumothorax dextra. C and D are thorax ctscan on april $18^{\text {th }} 2018$ revealed right-sided hydropneumothorax. 


\section{Discussion}

Definitve diagnosis of pleural tuberculosis is by the finding of mycobacterium tuberculosis in pleural biopsy, or M.Tuberculosis culture and drug sensitivy test. But this was difficult to perform by physician. $^{2}$ The primary indication for decortication and adhesiolysis in a patients with reccurent hydropneumothorax is a presence of symptoms due to lung restriction resulting from development of thick fibrinous peel. ${ }^{4}$ Decortication is frequently necessary when other minor interventions (eg, chest tube) did'nt have resulted. ${ }^{4}$ The etiology of an pleural effusion can be difficult to classify and often to requires both pleural fluid analysis and clinical correlation. ${ }^{5}$ Pleural fluid analysis of this patient revealed glucose 94 mg/dl, LDH 1249 IU/L, protein 4,8 g/dl, leucocytes 13.937/ $\mu \mathrm{L}$. Based on pleural fluid analysis, clinical correlation and flowchart of tuberculosis diagnosed from Indonesia national tuberculosis programmed, the physician decide to give OAT $2^{\text {nd }}$ category. ${ }^{6}$ Finally, after four times reccurent hydropneumothorax, the patient shows significant improvement in clinical condition, radiology finding (figure 4), and lung fuction test after finished the tuberculosis treatment.

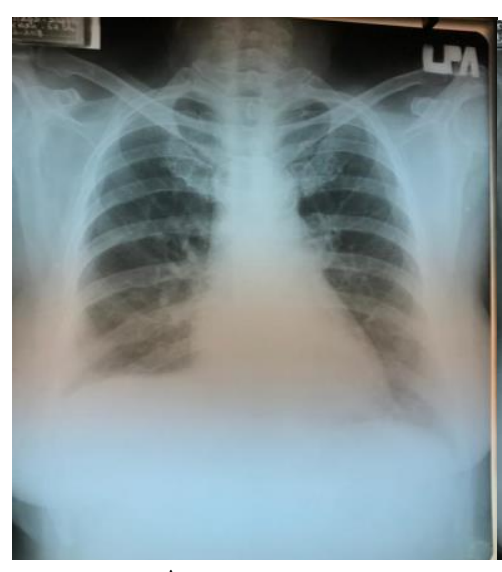

A

\section{1}

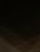

\section{ins:}

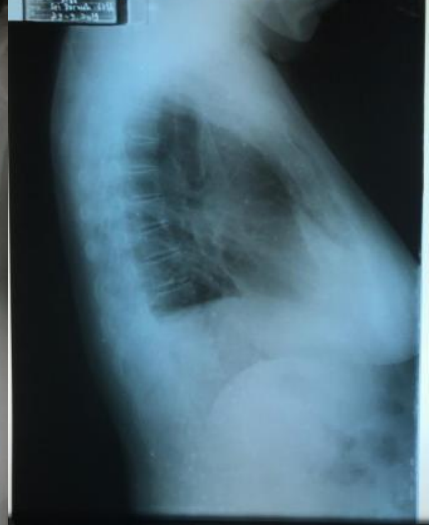

B

Figure 4. Radiology Imaging (after OAT $2^{\text {nd }}$ category)

A. Chest x-ray at december $4^{\text {th }} 2018$ (8 months with OAT $2^{\text {nd }}$ category) shows normal cxr, B. Chest x-ray at March $23^{\text {th }} 2019$ (after complete OAT 2nd category) shows normal CXR.

\section{Summary}

A 60 year old woman with four times reccurent right-sided hydropneumothorax, the etiology of reccurent hydropneumothorax is tuberculosis infection. Providing anti tuberculosis medication based on clinically finding, evaluation of chest x-ray and microbiology are essential to prevent progression of the disease. 


\section{References}

1. Gui X, Xiao H. Diagnosis of tuberculosis pleurisy with adenosine deaminase (ADA): A systematic review and meta-analysis. Int J Clin Exp Med. 2014;7(10):3126-35.

2. Havelock, T., Teoh, R., Laws, D., Gleeson, F. 2010. Pleural procedures and thoracic ultrasound: BritishThoracic Society pleural disease guideline 2010. Thorax. 65(2): 61-76

3. Sharan, L.A., Price, T.P., Hehn, B., Manoff, D. and Cowan, S.W., 2016. A 22-year-old man with pleural tuberculosis associated hydropneumothorax: Case report and literature review. Respiratory medicine case reports, 18, pp.27-30.

4. Rodriguez EP, Light RW. Effusion from infections: tuberculosis, In:Light RW, Lee YCG, editors. Texbook of pleural disease, $2^{\text {nd }}$ ed. London: Hodder Arnold; 2008 p:367-75

5. Kamholz SL. Pleural Tuberculosis. In: Rom WN, Garay SM, editor. Tuberculosis. $2^{\text {nd }}$ ed. Philadelphia: Lippincott Williams \& Wilkins; 2004.p.497-504

6. Indonesia, Peraturan Pemerintah Republik. "Peraturan Menteri Kesehatan No.67 Tahun 2016 Tentang Penanggulangan Tuberculosis”. (2016) 